\title{
Efeitos da Raça e da Heterozigose sobre Características Ponderais de Bezerros Nelore e Mestiços Red Angus x Nelore
}

\author{
Daniel Perotto ${ }^{1}$, José Jorge dos Santos Abrahão ${ }^{2}$, Antonio Carlos Cubas ${ }^{3}$
}

RESUMO - $O$ efeito direto da raça Red Angus $\left(a_{R}^{1}\right)$, computado como desvio a partir do efeito direto Nelore $\left(a_{N}^{I}\right)$, e os efeitos das heterozigoses individual $\left(\mathrm{h}_{\mathrm{RN}}{ }^{\mathrm{I}}\right)$ e materna $\left(\mathrm{h}_{\mathrm{RN}}^{\mathrm{M}}\right)$, resultantes do cruzamento entre essas duas raças, foram estimados. Foi usado o método da regressão múltipla para analisar os pesos ao nascimento (PNT), à desmama (PDS) e aos 12 meses (P12M) e os ganhos de peso médios diários do nascimento à desmama (GMD_ND) e da desmama aos 12 meses (GMD_DA). Um total de 410 bezerros dos grupos Nelore, 1/2 Red Angus+1/2 Nelore, 3/4 Nelore+1/4 Red Angus e 3/4 Red Angus+1/4 Nelore, nascidos no período de 1985 a 1995, na Estação Experimental Paranavaí, no Noroeste do Estado do Paraná-Brasil, forneceu os dados para estudo. O PDS e o GMD_ND foram corrigidos para 205 dias de idade e o P12M e o GMD_DA, para 365 dias de idade. O efeito direto da raça Angus ( $\left.a_{R}^{I}\right)$ não mostrou significância para qualquer característica analisada. O efeito da heterozigose indivdual $\left(\mathrm{h}_{\mathrm{RN}}{ }^{1}\right)$ foi significativo para todas as características, exceto para o PNT. Os coeficientes de regressão parcial do PDS, GMD_ND, P12M e GMD_DA sobre a fração esperada de loci heterozigotos no genótipo do bezerro foram: $31 \pm 6 \mathrm{~kg}, 0,143 \pm 0,028 \mathrm{~kg}, 55 \pm 7 \mathrm{~kg}$ e $0,126 \pm 0,032 \mathrm{~kg}$. O efeito da heterozigose materna $\left(\mathrm{h}_{\mathrm{RN}}^{\mathrm{M}}\right)$ mostrou significância para PNT, PDS, GMD_ND e P12M. Os correspondentes coeficientes de regressão parcial foram 2,8 $\pm 0,7 \mathrm{~kg}, 27 \pm 4 \mathrm{~kg}, 0,117 \pm 0,019 \mathrm{~kg}$ e $19 \pm 5 \mathrm{~kg}$.

Palavras-chave: efeitos aditivos, heterozigose, Nelore, Red Angus

\section{Breed and Heterozygosity Effects on Body Weight Traits of Nellore and Crossbred Red Angus x Nellore Calves}

\begin{abstract}
The direct effect of Red Angus $\left(a_{R}\right)$, computed as deviation from the direct effect of Nellore $\left(a_{N}^{I}\right)$, and the effects of individual $\left(\mathrm{h}_{\mathrm{RN}}{ }^{1}\right)$ and maternal $\left(\mathrm{h}_{\mathrm{RN}}{ }^{\mathrm{M}}\right)$ heterozygosity, resulting from crossing these breeds were estimated. The multiple regression method was used to analyze birth weight (PNT), weaning weight (PDS), yearling weight (P12M), and for the daily weight gain from birth to weaning time (GMD_ND) and from weaning to 12 months (GMD_DA). A total of 410 calves from the groups of Nellore, 1/2 Red Angus+1/2 Nellore, 3/4 Nellore+1/4 Red Angus and 3/4 Red Angus+1/4 Nellore, raised at Estação Experimental Paranavaí, in the North-West of Paraná State-Brazil, from 1985 to 1995, supplied the data for the study. Weaning weight and GMD_ND were corrected for 205 days of age and P12M and GMD_DA were corrected for 365 days of age. The direct effect of the Angus breed $\left(a_{R}{ }^{1}\right)$ did not show significance for any of the studied traits. The individual heterozygosity effect $\left(h_{R N}{ }^{1}\right)$ was significant for all traits, except for PNT. The partial regression coefficients of PDS, GMD_ND, P12M and GMD_DA upon the expected fraction of heterozygous loci in the genotypes of the calves were $31 \pm 6 \mathrm{~kg}, .143 \pm .028 \mathrm{~kg}, 55 \pm 7 \mathrm{~kg}$ and $.126 \pm .032 \mathrm{~kg}$. The maternal heterozygosity effect $\left(\mathrm{h}_{\mathrm{RN}}^{\mathrm{M}}\right)$ was significant for PNT, PDS, GMD_ND and P12M. The corresponding partial regression coefficients were $2.8 \pm 0.7 \mathrm{~kg}, 27 \pm 4 \mathrm{~kg}, .117 \pm .019 \mathrm{~kg}$ and $19 \pm 4 \mathrm{~kg}$.
\end{abstract}

Key Words: additive effects, heterozygosity, Nellore, Red Angus

\section{Introdução}

O cruzamento de raças taurinas com raças zebuínas representa uma das estratégias de melhoramento genético dos rebanhos bovinos de corte do Brasil Central (BARBOSA e ALENCAR, 1995). Essa estratégia pode ser empregada como forma de implementação de esquemas sistemáticos de cruzamentos visando à exploração da heterose e da complementaridade (CARTWRIGHT, 1971) ou como passo inicial para a formação de populações sintéticas (GREGORY et al., 1994).

Em qualquer dos casos, a adoção de cruzamentos deve embasar-se em estimativas das diferenças raciais para as características de interesse econômico, dos níveis de heterose nessas características em função das raças envolvidas e das bases genéticas da heterose (DICKERSON, 1973). A formação de populações sintéticas é uma estratégia recomendada para os casos em que houver grandes diferenças 
individuais e maternas entre as raças envolvidas e a heterose for conseqüência da ação gênica da dominância (KOCH et al., 1989).

Os trabalhos de pesquisa em cruzamentos de bovinos de corte no Brasil Central têm enfatizado a caracterização biológica de raças e de cruzamentos para características de relevância econômica (RAZOOK et al., 1986; EUCLIDES FILHO et al., 1996; e PEROTTO et al., 1996). De modo geral, os resultados desses trabalhos revelam a superioridade dos mestiços europeu x zebu em relação aos zebuínos puros para características como desenvolvimento ponderal, ganho de peso em confinamento, peso ao abate e produção de carne comestível. A superioridade de vacas cruzadas sobre vacas zebus para a idade ao primeiro parto, o intervalo de partos e o peso do bezerro à desmama também têm sido reportados (PEROTTO et al., 1994).

Por outro lado, são poucas as estimativas de heterose sobre características relevantes para a produção de carne bovina em cruzamentos Bos taurus $x$ Bos indicus no meio tropical brasileiro. Na revisão de BARBOSA e DUARTE (1989), apenas um trabalho (LOBO, 1989) fornece valores para a heterose sobre os pesos ao nascimento e à desmama em cruzamentos Caracu x Zebu em Ribeirão Preto - SP. As causas dessa lacuna de informação devem-se às dificuldades de se manter gado europeu puro sob as condições tropicais (SUNDSTROM et al., 1994).

Uma alternativa metodológica para estimar componentes genéticos do desempenho de mestiços consiste em se substituir, no modelo estatístico, os efeitos fixos de grupo genético por uma série de coeficientes de regressão parcial do desempenho sobre as frações esperadas dos efeitos aditivos, heterozigóticos e epistáticos nos genótipos dos animais. Vários autores (DILLARD et al., 1980; ROBISON et al., 1981; e ALENCAR et al., 1995) têm empregado essa metodologia para analisar dados experimentais de cruzamentos com animais.

Os modelos genéticos usados para representar o desempenho de mestiços variam quanto aos componentes incluídos. CUNNINGHAM (1982) e KRESS et al. (1986), com base em evidências experimentais de associação linear entre heterose e heterozigose, para grande número de características em bovinos de corte, propõem o modelo aditivo-dominante. Contudo, desvios a partir desse modelo foram encontrados para algumas características (KOCH et al., 1985; MORRIS et al., 1986). Em termos gerais, o modelo aditivo-dominante descreve adequadamente o de- sempenho de diferentes grupos genéticos, para a maioria das características de importância econômica, e pode ser usado com segurança na predição do desempenho de diferentes estratégias de utilização de recursos genéticos (KRESS et al., 1986).

O presente estudo foi conduzido para estimar os efeitos raciais diretos e os efeitos da heterozigose individual e materna sobre os pesos corporais e os ganhos de peso até um ano de idade em bezerros mestiços Red Angus x Nelore criados em ambiente subtropical na região Noroeste do Estado do Paraná.

\section{Material e Métodos}

Foram analisadas 401 observações de peso ao nascimento (PNT), 385 observações de peso à desmama (PDS) e de ganho de peso médio diário do nascimento à desmama (GMD_ND) e 350 observações de peso aos 12 meses (P12M) e de ganho de peso médio diário da desmama aos 12 meses (GMD_DA) de bezerros, de ambos os sexos, pertencentes a quatro grupos genéticos [Nelore $(\mathrm{N})$, 1/2 Red Angus + 1/2 Nelore, (1R1N), 3/4 Nelore + 1/4 Red Angus (3N1R) e 3/4 Red Angus + 1/4 Nelore (3R1N)], nascidos de 1985 a 1995, na Estação Experimental de Paranavaí. A região apresenta clima Cfa da classificação de Köeppen (IAPAR, 1994) e solos dos grupos Latosol Vermelho Escuro Distrófico e Podzólico Vermelho Amarelo (MINISTÉRIO DA AGRICULTURA, 1970).

A distribuição de animais por grupo genético é mostrada na Tabela 1 . Os animais $\mathrm{N}$ e $1 \mathrm{R} 1 \mathrm{~N}$ foram gerados pelo acasalamento, por intermédio da inseminação artificial de vacas $\mathrm{N}$ com touros N e Red Angus (R), respectivamente. Numa segunda etapa, vacas $\mathrm{N}$ e $1 \mathrm{R} 1 \mathrm{~N}$ foram acasaladas com touros $\mathrm{N}$ e $\mathrm{R}$ para produzir animais $3 \mathrm{~N} 1 \mathrm{R}$ e $3 \mathrm{R} 1 \mathrm{~N}$ ao mesmo tempo em que animais $\mathrm{N}$ e 1R1N continuaram sendo produzidos. Tal procedimento resultou em distribuição com número desigual de observações por ano de nascimento, mês de nascimento e ordem de parto. As observações pertinentes aos grupos N e 1R1N apresentaram distribuições uniformes nos diferentes níveis desses fatores categóricos. Por outro lado, as distribuições das observações pertinentes aos grupos 3N1R e $3 \mathrm{R} 1 \mathrm{~N}$ concentraram-se em apenas alguns níveis dos fatores ano, mês e ordem de parto, não havendo, entretanto, confundimento de grupo genético com qualquer desses efeitos. No total, os bezerros representaram progênies de 33 touros $\mathrm{N}$ e de 15 touros $\mathrm{R}$.

As mães desses bezerros foram mantidas em 
506 Rev. bras. zootec.

Tabela 1 - Número de animais por grupo genético e valores dos coeficientes dos efeitos genéticos

Table 1 - Number of animals and coefficient of genetic effects according to genetic group

\begin{tabular}{|c|c|c|c|c|c|}
\hline \multirow[t]{2}{*}{$\begin{array}{l}\text { Grupo genético }{ }^{1} \\
\text { Genetic group }^{1}\end{array}$} & \multirow[t]{2}{*}{$\begin{array}{l}\text { Número de animais } \\
\text { Number of animals }\end{array}$} & \multicolumn{4}{|c|}{$\begin{array}{l}\text { Coeficiente dos efeitos genéticos }{ }^{2} \\
\text { Coefficient of genetic effects }{ }^{2}\end{array}$} \\
\hline & & $\mathrm{f}_{\mathrm{i}}$ & $\mathrm{f}_{\mathrm{i}}^{*}$ & $\mathrm{f}_{\mathrm{ij}}$ & $\mathrm{f}_{\mathrm{ij}}{ }^{*}$ \\
\hline $\mathrm{N}$ & 198 & 0,00 & 0,00 & 0,00 & 0,00 \\
\hline 1R1N & 141 & 0,50 & 0,00 & 1,00 & 0,00 \\
\hline $3 \mathrm{~N} 1 \mathrm{R}$ & 45 & 0,25 & 0,50 & 0,50 & 1,00 \\
\hline 3R1N & 26 & 0,75 & 0,50 & 0,50 & 1,00 \\
\hline
\end{tabular}

${ }^{1} \mathrm{~N}=$ Nelore, $1 \mathrm{R} 1 \mathrm{~N}=1 / 2$ Red Angus + 1/2 Nelore, 3N1R = 3/4 Nelore + 1/4 Red Angus, 3R1N = 3/4 Red Angus + 1/4 Nelore.

$2 f_{i}=$ fração esperada de genes da raça Red Angus na composição racial do animal, $f_{i}^{*}=$ fração esperada de genes da raça Red Angus na composição racial da mãe do animal, $f_{\mathrm{ij}}=$ fração esperada de loci no genótipo do animal com um gene originário da raça Red Angus e o outro da raça Nelore e $f_{\mathrm{ij}}{ }^{*}=$ fração esperada de loci no genótipo da mãe do animal com um gene originário da raça Red Angus e outro da raça Nelore.

${ }_{1} N=$ Nellore, $1 R 1 \mathrm{~N}=1 / 2$ Red Angus $+1 / 2$ Nellore, 3N1R = 3/4 Nellore + 1/4 Red Angus, 3R1N = 3/4 Red Angus + 1/4 Nellore.

$2 f_{\mathrm{i}}=$ expected fraction of Red Angus genes in the genotype of the animal, $f_{\mathrm{i}}^{*}=$ expected fraction of Red Angus genes in the genotype of the dam, $\mathrm{f}_{\mathrm{ij}}$ $=$ expected fraction of loci in the genotype of the animal with one gene from Red Angus and the other from Nellore and $f_{\mathrm{ij}}^{*}=$ expected fraction of loci in the genotype of the dam with one gene from Red Angus and the other from Nellore.

pastagens de Brachiaria humidicula e Brachiaria decumbens, tendo sido suplementadas no inverno com forragem picada de capim napier (Pennisetum purpureum) e cana-de-açúcar (Saccharum officinarum), além de uréia adicionada à mistura mineral e pastoreio direto em bancos de proteína (Cajanus indicus e Leucaena leucocephala). Os bezerros foram desmamados aproximadamente aos sete meses de idade e separados por sexo entre os 11 e 12 meses de idade. Durante o primeiro inverno após a desmama, os bezerros tiveram acesso a pastagens de aveia (Avena sativa) à razão de duas horas por dia.

A reprodução foi feita por inseminação artificial em duas estações de inseminação, no período de $1^{\circ}$ de outubro a 30 de janeiro e de $1^{\circ}$ de abril a 30 de junho. Um mínimo de cinco touros por raça foi usado anualmente, sendo que pelo menos um touro de cada raça era repetido em anos consecutivos. $\mathrm{O}$ sêmen utilizado foi adquirido nas centrais de inseminação comerciais que operam no Brasil.

O rebanho experimental foi mantido sob rígido controle sanitário que incluiu desverminações e pulverizaões periódicas para combater endo e ectoparasitos, além das vacinações contra aftosa, brucelose, carbúnculo hemático e paratifo dos bezerros.

Os dados de cada característica foram analisados pelo método dos quadrados mínimos (SAS, 1985), ajustando-se o seguinte modelo linear:

$Y_{i j k l}=\mu+M_{i}+A_{j}+S_{k}+a_{R}^{I} f_{i}+h_{R N}^{I} f_{i j}+h_{R N}^{M} f_{i j}^{*}+\varepsilon_{i j k l}$

em que

$\mathrm{Y}_{\mathrm{ijkl}}=$ valor observado para a característica (PNT, PDS, GMD_ND, P12M e GMD_DA) no 1-ésimo animal, do k-ésimo sexo, nascido no j-ésimo ano e no i-ésimo mês;

$\mu=$ média geral da característica $Y$;

$\mathrm{M}_{\mathrm{i}}=$ efeito fixo do i-ésimo mês de nascimento do animal $(i=1,2,3,4,7, \ldots, 12)$;

$\mathrm{A}_{\mathrm{j}}=$ efeito fixo do j-ésimo ano de nascimento do $\operatorname{animal}(\mathrm{j}=1985, \ldots, 1995)$;

$\mathrm{S}_{\mathrm{k}}=$ efeito fixo do k-ésimo sexo do bezerro

$(\mathrm{k}=1$, macho e $\mathrm{k}=2$, fêmea);

$a_{\mathrm{R}}^{\mathrm{I}}=$ coeficiente de regressão parcial de $\mathrm{Y}$ sobre $\mathrm{f}_{\mathrm{i}}$;

$f_{\mathrm{i}}=$ fração esperada de genes da raça Red Angus na composição racial do animal (Tabela 1);

$\mathrm{h}_{\mathrm{RN}}{ }^{\mathrm{I}}=$ coeficiente de regressão parcial de $\mathrm{Y}$ sobre $\mathrm{f}_{\mathrm{ij}}$;

$f_{\mathrm{ij}}=$ fração esperada de loci no genótipo do animal com um gene originário da raça Red Angus e outro da raça Nelore (Tabela 1);

$\mathrm{h}_{\mathrm{RN}}{ }^{\mathrm{M}}=$ coeficiente de regressão parcial de $\mathrm{Y}$ sobre $\mathrm{f}_{\mathrm{ij}}{ }^{*}$;

$f_{\mathrm{ij}}{ }^{*}=$ fração esperada de loci no genótipo da mãe do animal com um gene originário da raça Red Angus e outro da raça Nelore (Tabela 1); e

$\varepsilon_{\mathrm{ijkl}}=$ erro aleatório associado a cada valor observado.

Além desses efeitos, a ordem de parto (OP), com 11 níveis, foi incluída na análise do PNT. Os efeitos linear (IDM) e quadrático (IDMQ) da idade da mãe ao nascimento do bezerro foram usados como covariáveis nas análises do PDS e do GMD_ND.

Pelo modelo estatístico-genético acima definido, $\mathrm{a}_{\mathrm{R}}{ }^{\mathrm{I}}$, ou seja, o efeito direto da raça Red Angus, é estimado como desvio a partir do efeito direto da raça Nelore $\left(a_{N}{ }^{I}\right) \cdot h_{R N}$ i pode ser interpretado como o efeito da heterose direta ou individual desde que esta possa ser atribuída à ação gênica da dominância. $\mathrm{O}$ efeito da heterozigose materna $\left(\mathrm{h}_{\mathrm{RN}}{ }^{\mathrm{M}}\right)$ pode também 
ser interpretado como o efeito materno-aditivo da raça Red Angus $\left(a_{R}{ }^{M}\right)$, estimado como desvio a partir do correspondente efeito da raça Nelore $\left(a_{N}{ }^{M}\right)$. Isto se deve à completa dependência entre esses efeitos nos grupos genéticos representados neste estudo. Antes de submetidos às análises de variância, o PDS e o GMD_ND foram padronizados para 205 dias de idade, ao passo que o P12M e o GMD_DA foram padronizados para 365 dias de idade. Essas padronizações foram feitas utilizando-se os ganhos médios diários individuais do nascimento à desmama e da desmama ao ano, respectivamente, de conformidade com as fórmulas preconizadas pelo Ministério da Agricultura e do Abastecimento (MINISTÉRIO DA AGRICULTURA E DO ABASTECIMENTO, 1998).

\section{Resultados e Discussão}

Os resumos das análises de variância das cinco características são apresentados na Tabela 2. Os valores dos coeficientes de determinação estatística indicam que, exceto para o PNT, as variâncias totais das características em estudo foram bem descritas pelos modelos.
O efeito da ordem de parto sobre o PNT foi altamente significativo. Bezerros nascidos do segundo ao sexto parto foram mais pesados ao nascimento que os dos demais partos.

$\mathrm{O}$ mês de nascimento do bezerro teve influência $(\mathrm{P}<0,001)$ sobre o PDS, o GMD_ND, o P12M e o GMD_DA. Animais nascidos de julho a novembro apresentaram melhores desempenhos quanto ao GMD_ND e ao PDS que bezerros nascidos de dezembro a abril. Por outro lado, bezerros nascidos de dezembro a abril apresentaram melhor ganho da desmama aos 12 meses e, conseqüentemente, maior $\mathrm{P} 12 \mathrm{M}$ que os nascidos no inverno e primavera.

$\mathrm{O}$ ano de nascimento influenciou todas as características analisadas. Não se observou tendência de melhoria do peso à desmama com o passar dos anos. Entretanto, o P12M dos bezerros nascidos a partir de 1992 foi mais elevado que o de bezerros nascidos nos anos anteriores (1985 a 1991). Isso pode ser atribuído a melhorias nos pastos destinados à recria dos animais.

Igualmente, o sexo do bezerro teve efeito significativo $(\mathrm{P}<0,001)$ sobre todas as características, sendo que os machos superaram as fêmeas em $1,89 \pm 0,36 \mathrm{~kg}$ para o PNT, 11,03 $\pm 2,00 \mathrm{~kg}$ para o PDS, $0,043 \pm 0,009 \mathrm{~kg}$

Tabela 2 - Resumo das análises de variância de características ponderais em bovinos Nelore e em mestiços Red Angus $\mathrm{x}$ Nelore em Paranavaí-PR

Table 2 - Summary of analyses of variance of body weight traits of Nellore and crossbred Red Angus $x$ Nellore calves in Paranavaí-PR Fonte de variação ${ }^{1,2}$

Source of variation ${ }^{1,2}$ $\begin{array}{cc}\mathrm{gl} & \text { Valor do F computado } \\ \mathrm{df} & \text { Computed } F \text { value }\end{array}$

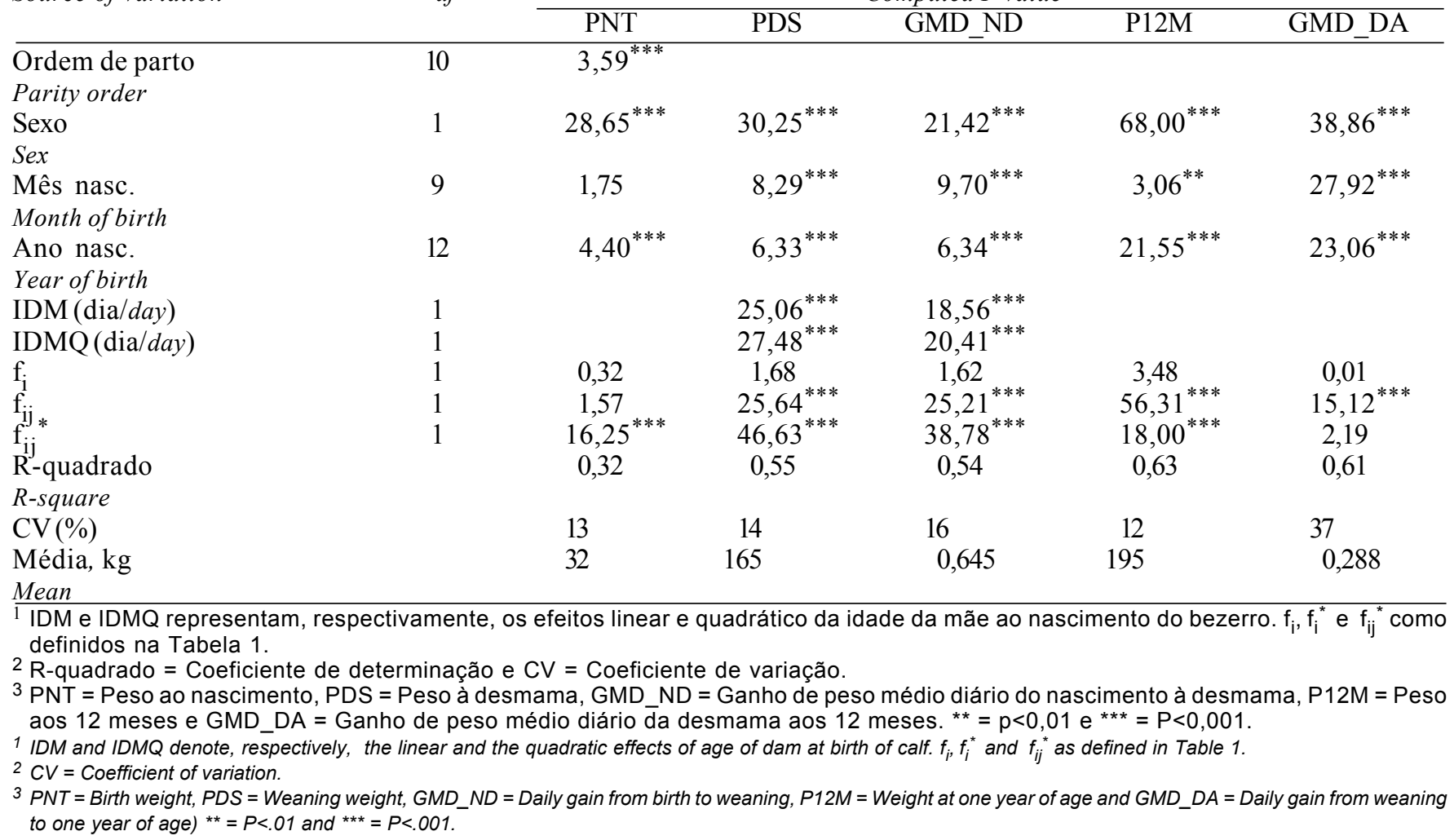


508 Rev. bras. zootec.

para o GMD_ND, $20,63 \pm 2,50 \mathrm{~kg}$ para o P12M e $0,069 \pm 0,011 \mathrm{~kg}$ para o GMD_DA.

Os coeficientes de regressão parcial do PDS sobre IDM e IDMQ foram, respectivamente, $0,027 \pm 0,005 \mathrm{~kg} \mathrm{e}-47 \times 10^{-7} \pm 90 \times 10^{-8} \mathrm{~kg}$, ambos significativos $(\mathrm{P}<0,001)$. Na mesma ordem, os coeficientes de regressão parcial do GMD_ND sobre as duas covariáveis foram: $110 \times 10^{-5} \pm 26 \times 10^{-6} \mathrm{~kg}(\mathrm{P}<0,001) \mathrm{e}$ $-19 \times 10^{-9} \pm 10 \times 10^{-10} \mathrm{~kg}(\mathrm{P}<0,001)$.

$\mathrm{Na}$ Tabela 3 encontram-se as estimativas dos efeitos genéticos incluídos no modelo estatístico sobre as características analisadas. Os resultados mostram que o aumento da proporção de genes de Red Angus no genótipo do bezerro não teve efeito sobre qualquer das cinco características, embora, para o P12M, este efeito se aproximou do nível de significância de $5 \%(\mathrm{P}<0,07)$. A heterozigose do indivíduo $\left(\mathrm{f}_{\mathrm{ij}}\right)$ mostrou efeito positivo e significativo $(\mathrm{P}<0,001)$ sobre todas as características, exceto sobre o PNT. Os altos valores das estimativas do coeficiente $\mathrm{h}_{\mathrm{RN}} \mathrm{I}$ evidenciam a importância da exploração da heterose na melhoria do desempenho dos rebanhos de cria nas regiões subtropicais do Brasil. Os efeitos da heterozigose materna $\left(\mathrm{h}_{\mathrm{RN}}{ }^{\mathrm{M}}\right)$ foram significativos $(\mathrm{P}<0,001)$ sobre o PNT, o PDS, o GMD_ND e o P12M. Não se verificou qualquer efeito da heterozigose da mãe sobre o GMD_DA. Assim, a significância estatística de $\mathrm{h}_{\mathrm{RN}}{ }^{\mathrm{M}}$ sobre o $\mathrm{P} 12 \mathrm{M}$ pode ser atribuída, em grande parte, à importância desse efeito sobre o PDS, já que este representou, no presente estudo, $85 \%$ do P12M. Caso se quisesse interpretar $h_{R N} M$ como o efeito materno da raça Red Angus $\left(a_{A}{ }^{M}\right)$, calculado como desvio a partir do efeito materno da raça Nelore, os valores da respectiva coluna da Tabela 3 deveriam ser multiplicados por 2. As correlações genéticas negativas entre o efeito direto e o efeito materno, encontradas em alguns casos para o peso ao nascimento e na maioria dos casos para ganho até a desmama (KOCH, 1972), poderiam explicar a inversão de sinais entre $a_{R}{ }^{I} e$ $\mathrm{h}_{\mathrm{RN}}{ }^{\mathrm{M}}$, para essas características, no presente estudo.

Os resultados encontrados para as estimativas de $\mathrm{h}_{\mathrm{RN}}{ }^{\mathrm{I}}$ e $\mathrm{h}_{\mathrm{RN}}{ }^{\mathrm{M}}$ estão de acordo com evidências experimentais (GREGORY e CUNDIFF, 1980; PEROTTO et al. 1998a), indicando que maior produtividade dos rebanhos de cria de bovinos de corte pode ser alcançada pela implementação de sistemas de cruzamentos que explorem simultaneamente os efeitos da heterose na mãe e no bezerro.

A Tabela 4 mostra as diferenças entre as médias de cada grupo mestiço presente no estudo e a média do Nelore para cada uma das características estudadas. A diferença $1 \mathrm{R} 1 \mathrm{~N}-\mathrm{N}$ foi significativa $(\mathrm{P}<0,05)$ para o PNT e altamente significativa $(\mathrm{P}<0,001)$ para as demais características. Essa diferença é definida pela função linear $\left(0,5 \mathrm{a}_{\mathrm{R}}^{\mathrm{I}}+1,0 \mathrm{~h}_{\mathrm{RN}}^{\mathrm{I}}\right)$ e encerra, portanto, efeitos genéticos diretos e heterozigóticos individuais. Como $a_{\mathrm{R}}{ }^{\mathrm{I}}$ não alcançou significância estatística para qualquer das cinco características, as diferenças observadas podem ser atribuídas, em grande parte, à heterozigose do bezerro.

A diferença 3N1R-N, definida pela função linear $\left(0,25 \mathrm{a}_{\mathrm{R}}^{\mathrm{I}}+0,5 \mathrm{~h}_{\mathrm{RN}}^{\mathrm{I}}+1,0 \mathrm{~h}_{\mathrm{RN}}{ }^{\mathrm{M}}\right)$, foi altamente significativa para PNT, PDS, GMD_ND e P12M. Para estas características, a superioridade do $3 \mathrm{~N} 1 \mathrm{R}$ em relação ao $\mathrm{N}$ pode ser atribuída em parte à heterozigose

Tabela 3 -Estimativa de efeitos genéticos em características ponderais em bezerros Nelore e em mestiços Red Angus x Nelore em Paranavaí-PR

Table 3 - Estimate of genetic effects on body weight traits of Nellore and crossbred Red Angus x Nellore calves in Paranavaí-PR

Característica

Trait

\begin{tabular}{lrrr} 
& \multicolumn{1}{c}{$\mathrm{a}_{\mathrm{R}}^{\mathrm{I}}$} & \multicolumn{1}{c}{$\mathrm{h}_{\mathrm{RN}}^{\mathrm{I}}$} & \multicolumn{1}{c}{$\mathrm{h}_{\mathrm{RN}}^{\mathrm{M}}$} \\
\cline { 2 - 4 } PNT(kg) & $-1,157 \pm 2,061$ & $1,357 \pm 1,083$ & $2,772 \pm 0,687^{* * *}$ \\
PDS(kg) & $-14,928 \pm 11,528$ & $30,553 \pm 6,033^{* * *}$ & $27,199 \pm 3,983^{* * * *}$ \\
GMD_ND(kg) & $-0,069 \pm 0,054$ & $0,143 \pm 0,028^{* * *}$ & $0,117 \pm 0,019^{* * *}$ \\
P12M(kg) & $-25,931 \pm 13,898$ & $54,964 \pm 7,324^{* * *}$ & $19,268 \pm 4,542^{* * *}$ \\
GMD_DA(kg) & $-0,006 \pm 0,061$ & $0,126 \pm 0,032^{* * *}$ & $-0,029 \pm 0,020$
\end{tabular}

1 PNT = peso ao nascimento, PDS = peso à desmama, GMD_ND = ganho de peso médio diário do nascimento à desmama, $\mathrm{P} 12 \mathrm{M}=$ peso aos 12 meses de idade e GMD_DA = ganho de peso médio diário da desmama aos 12 meses de idade.

$2 \mathrm{a}_{\mathrm{R}}{ }_{\mathrm{R}}=$ efeito genético direto da raça Red Angus, $\mathrm{h}_{\mathrm{RN}}{ }^{1}=$ efeito da heterozigose individual entre Red Angus e Nelore, $h_{\mathrm{RN}}{ }^{M}=$ efeito da heterozigose materna entre Red Angus e Nelore. ${ }^{* * *}=\mathrm{P}<0,001$ pelo teste $\mathrm{t}$.

$1 P N T=$ birth weight, $P D S=$ weaning weight, GMD_ND = daily gain from birth to weaning, $P 12 M=$ yearling weight and $G M D \_D A=$ daily gain from weaning to one year of age.

${ }^{2} \mathrm{a}_{\mathrm{R}}^{\mathrm{I}}=$ direct effect of Red Angus, $\mathrm{h}_{\mathrm{RN}}{ }^{1}=$ individual heterozygotic effect between Red Angus and Nellore, $\mathrm{h}_{\mathrm{RN}}{ }_{\mathrm{M}}^{\mathrm{M}}=$ maternal heterozygotic effect between Red Angus and Nellore. ${ }^{* * *}=P<.001$ by $t$ test. 
Tabela 4 - Diferença entre mestiços Red Angus x Nelore e Nelore para características ponderais em Paranavaí-PR Table 4 - Difference between crossbred Red Angus $x$ Nellore and Nellore for body weight traits in Paranavai-PR

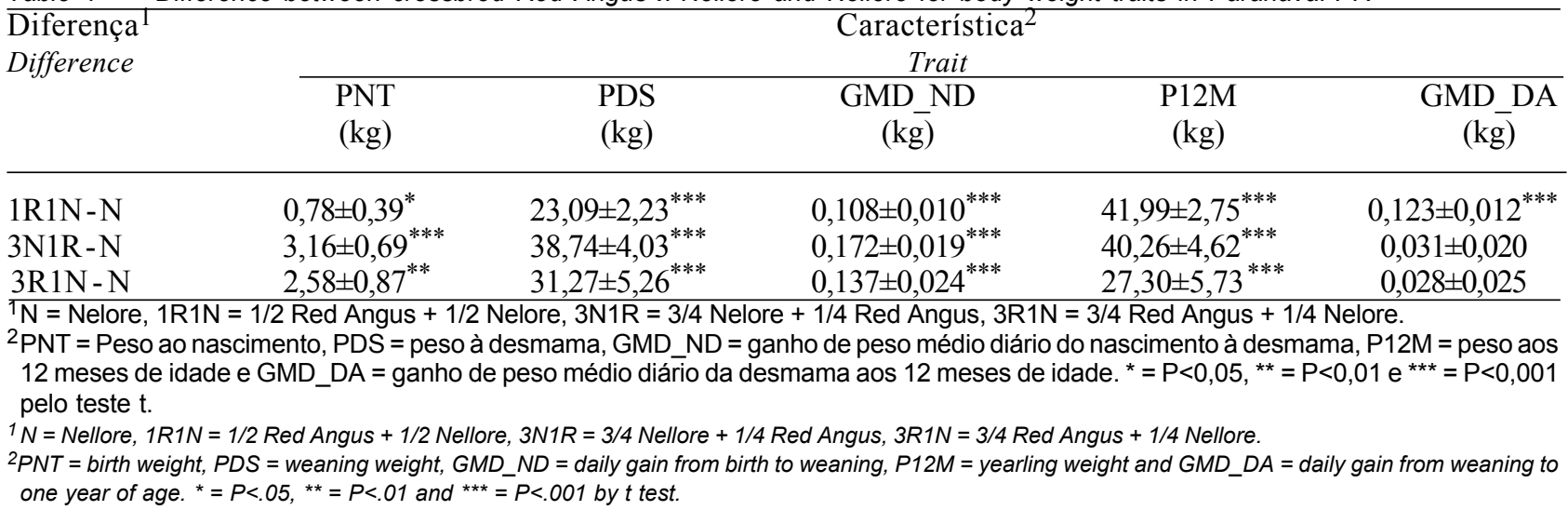

individual, mas principalmente à heterozigose materna. O 3R1N também superou o Nelore para PNT, PDS, GMD_ND e P12M e uma vez mais a diferença é função das heterozigoses individual e materna, com maior participação da última.

Os resultados da Tabela 4 mostram ainda que não houve significância estatística para os contrastes 3N1R-N e 3R1N-N com respeito ao GMD_DA. Estes resultados são compatíveis com a menor participação da heterozigose individual no genótipo dos retrocruzados e com a falta de significância estatística do efeito da heterozigose materna na expressão dessa característica.

Em termos das médias dos respectivos grupos genéticos, os resultados da Tabela 4 indicam que o 3N1R supera o $1 \mathrm{~N} 1 \mathrm{R}$ para o PNT, o PDS e o GMD_ND, enquanto o oposto ocorre para o GMD_DA. Estes resultados estão inteiramente de acordo com os de SILVA e PEREIRA (1986) para cruzamentos Chianina x Nelore no Estado da Bahia, bem como com os resultados de EUCLIDES FILHO et al. (1996) para cruzamentos Fleckvieh x Nelore, Chianina x Nelore e Charolês x Nelore no Mato Grosso do Sul. Tais resultados suportam a hipótese de que a heterozigose materna é mais importante para o ganho até a desmama, enquanto a heterozigose individual, que é máxima quando a proporção de genes de Bos taurus no genótipo do bezerro é 50\%, é mais importante para o ganho após a desmama.

O grupo 3R1N manteve bom desempenho até a desmama, possivelmente em razão de as mães serem 1R1N. Entretanto, com respeito ao ganho após a desmama, esse grupo não diferiu do Nelore, o que sugere que $75 \%$ de genes Red Angus no genótipo dos bezerros já são suficientes para comprometer a adaptação dos animais ao meio tropical. Desenvolvimento ponderal de animais $3 / 4$ europeu $+1 / 4$ zebu inferior ao de animais $1 / 2$ europeu $+1 / 2$ zebu, em condições subtropicais do sul dos Estados Unidos, foi reportado por TURNER (1973) e PEACOCK et al. (1973) e corroboram a sugestão acima de que uma proporção de genes de Bos taurus próxima a $50 \%$ resulta em melhor desempenho animal em pastagens nesses ambientes.

As estimativas das diferenças $1 \mathrm{R} 1 \mathrm{~N}-\mathrm{N}, 3 \mathrm{~N} 1 \mathrm{R}$ $\mathrm{N}$ e 3R1N - N apresentadas na Tabela 4 são numericamente iguais às que seriam obtidas pelo contraste das respectivas médias dos grupos computadas a partir de um modelo incluindo o efeito fixo de grupo genético em vez dos coeficientes de regressão parcial. Entretanto, o modelo com o efeito fixo de grupo genético não permitiria estimar os efeitos genéticos diretos e heterozigóticos aqui estimados, porque o delineamento experimental não inclui todos os grupos genéticos necessários para tanto. A equivalência entre o método da regressão múltipla e o método do efeito fixo de grupo genético é demonstrada, com a presença dos necessários grupos no delineamento experimental, por PEROTTO et al. (1998b).

Supondo-se que o modelo genético proposto descreve adequadamente os dados, as estimativas da Tabela 3 podem ser usadas para montar equações preditivas do desempenho de grupos genéticos de interesse, porém não contemplados no experimento. Assim, para se predizer o PDS de determinado grupo, expresso como diferença a partir do PDS do Nelore, usar-se-ia a equação:

$$
\hat{u}_{i}=\mu_{N}-14,93 f_{i}+30,55 f_{i j}+27,20 f_{i j}^{*}
$$

em que

$\hat{\mathrm{u}}_{\mathrm{i}}=$ Valor predito para o peso à desmama do 
grupo i;

$\mu_{\mathrm{N}}=$ Média do peso à desmama do grupo Nelore;

$f_{\mathrm{i}}=$ Fração esperada de genes Red Angus nos animais do grupo $\mathrm{i}$;

$f_{\mathrm{ij}}=$ Coeficiente de heterozigose dos animais do grupo i; e

$f_{\mathrm{ij}}{ }^{*}=$ Coeficiente de heterozigose das mães dos animais do grupo $i$.

Por exemplo, o valor predito $\left(\hat{\mathrm{u}}_{\mathrm{Fn}}\right)$ do PDS de uma população sintética (Fn), resultante do contínuo interacasalamento de animais com $50 \%$ de genes Red Angus e 50\% de genes Nelore seria dado por:

$$
\hat{u}_{F n}=\mu_{N}-14,93(0,5)+30,55(0,5)+27,20(0,5)
$$

No presente estudo, as médias do Nelore foram $26,58 \pm 0,51 \mathrm{~kg}, 143,71 \pm 1,95 \mathrm{~kg}, 0,528 \pm 0,009 \mathrm{~kg}$, $194,64 \pm 2,50 \mathrm{~kg}$ e $0,245 \pm 0,014 \mathrm{~kg}$, respectivamente, para o PNT, PDS, GMD_ND, P12M e GMD_DA.

Com as estimativas apresentadas na Tabela 3, o desempenho esperado da população sintética acima referida, expresso como diferença a partir do Nelore, seria: $1,48 \pm 0,47 \mathrm{~kg}$ para o $P N T, 21,41 \pm 2,80 \mathrm{~kg}$ para o PDS, 0,095 $\pm 0,013 \mathrm{~kg}$ para o GMD_ND, 24,15 $\pm 3,10$ kg para o P12M e 0,045 $\pm 0,014 \mathrm{~kg}$ para o GMD_DA. As predições do PDS e do P12M dessa população representam, respectivamente, 92 e $65 \%$ da diferença 1R1N - N para essas características. Estes resultados dão suporte à formação de populações sintéticas como estratégia de utilização de recursos raciais para produção de carne bovina. Entretanto, uma conclusão definitiva sobre a viabilidade dessa estratégia para o melhoramento dos bovinos de corte do Brasil Central requer estimativas da retenção de heterose em gerações avançadas de cruzamentos, o que não é possível a partir do delineamento experimental que originou os dados usados no presente estudo.

Uma das limitações da equação de regressão estimada pela presente análise é que, a rigor, só poderia ser usada como equação preditiva para estimar valores esperados da variável dependente dentro da amplitude de variação da variável independente. Assim, a extrapolação para o nível 1,00 de $\mathrm{f}_{\mathrm{i}}$ deve ser vista com cautela, porque este nível não se encontra no delineamento experimental.

\section{Conclusões}

O efeito direto da raça Red Angus não foi significativo sobre os pesos ao nascimento, à desmama e aos 12 meses nem sobre os ganhos de peso até a desmama e da desmama aos 12 meses.

A heterozigose individual influenciou positivamente os pesos à desmama e aos 12 meses bem como os ganhos de peso do nascimento à desmama e da desmama aos 12 meses.

A heterozigose materna mostrou influência significativa e positiva sobre os pesos ao nascimento, à desmama e aos 12 meses e sobre o ganho de peso entre o nascimento e a desmama.

\section{Referências Bibliográficas}

ALENCAR, M.M., BARBOSA, P.F., TULLIO, R.R. et al. 1995. Peso à desmama de bezerros Canchim e cruzados Canchim x Nelore e Marchigiana x Nelore. R. Soc. Bras. Zootec., 24(6):917-925.

BARBOSA, P.F., DUARTE, F.A.M. Crossbreeding and new beef cattle breeds in Brazil. R. Bras. Genet., 12(3):257-301, September. 1989, Supplement.

BARBOSA, P.F., ALENCAR, M.M. Sistema de cruzamentos em bovinos de corte: Estado da arte e necessidades de pesquisa. In: REUNIÃO ANUAL DA SOCIEDADE BRASILEIRA DE ZOOTECNIA, 32, 1995, Brasília. Anais.. Brasília: SBZ, 1995. p.681-683.

CARTWRIGHT, T.C. 1971. Selection criteria for beef cattle for the future. J. Anim. Sci. 5(30):706-711.

KOCH, M.R. 1972. The role of maternal effects in animal breeding: VI. Maternal effects in beef cattle. J. Anim. Sci., 65(35):1316-1323.

CUNNINGHAM, E.P. The genetic basis of heterosis. In: WORLD CONGRESS ON GENETICS APPLIED TO LIVESTOCK PRODUCTION, 2, 1982, Madrid. Proceedings... Madrid: 1982. 7:190-205.

DICKERSON, G.E. Inbreeding and heterosis in animals. In: ANIMAL BREEDING AND GENETICS SYMPOSIUM IN HONOUR OF Dr. JAY L. LUSH.1973. Champaign. Proceedings... Champaign: Amer. Soc. Anim. Sci. 1973.p. 54-77.

DILLARD, E.U., RODRIGUEZ, O., ROBISON, O.W. 1980. Estimation of additive and nonadditive direct and maternal genetic effects from crossbreeding experiments. J. Anim. Sci., 50:4, 653-663.

EUCLIDES FILHO, K., FIGUEIREDO, G.R., SILVA, L.O.C. da et al. Pesos ao nascer e à desmama e ganho pré-desmama de Nelore e seus mestiços com Fleckvieh, Chianina, Charolês e Angus. In: REUNIÃO ANUAL DA SOCIEDADE BRASILEIRA DE ZOOTECNIA, 33, 1996, Fortaleza. Anais... Fortaleza: SBZ, 1996. p.164-166.

GREGORY, K.E., CUNDIFF, L.V. 1980. Crossbreeding in beef cattle: evaluation of systems. J. Anim. Sci., 51(5):1224-1242.

GREGORY, K.E., CUNDIFF, L.V., KOCH, R.M. Germplasm utilization in beef cattle. In: WORLD CONGRESS ON GENETICS APPLIED TO LIVESTOCK PRODUCTION, 5, 1994, Guelph. Proceedings... Guelph: University of Guelph, 1994. (17):261-268.

IAPAR. 1974. Cartas climáticas do Estado do Paraná. Documento 18. Londrina: Instituto Agronômico do Paraná. 49p.

KOCH, R.M., CUNDIFF, L.V., GREGORY, K.E. 1989. Beef cattle breed resource utilization. R. Bras. Genet., 12(3):5580(Supplement).

KOCH, R.M., DICKERSON, G.E., CUNDIFF, L.V. et al. 1985. 
Heterosis retained in advanced generations of crosses among Angus and Hereford cattle. J. Anim. Sci., 60(5):1117-1132.

KRESS, D.D., DOORNBOS, D.E., ANDERSON, D.C. Empirical validation of the dominance model for beef cattle. In: WORLD CONGRESS ON GENETICS APPLIED TO LIVESTOCK PRODUCTION, 3, 1986, Lincoln. Proceedings... Lincoln: University of Nebraska, 1986. 11:295-300.

LOBO, R.B. Análise genética e estatística de cruzamentos em dialelos. Departamento de Genética, Faculdade de Medicina de Ribeirão Preto-USP, SP. Relatório Técnico, 33p. 1989. (Mímeo).

MINISTÉRIO DA AGRICULTURA. Levantamento de Reconhecimento dos Solos do Noroeste do Estado do Paraná. Boletim Técnico n. 14, Rio de Janeiro: Ministério da Agricultura. 1970. 102p.

MINISTÉRIO DA AGRICULTURA E DO ABASTECIMENTO. 1998. Anual do Programa de Melhoramento Genético das Raças Zebuínas - 1998. Brasília: MA/SDR/DENACOOP. 96p.

MORRIS, C.A., BAKER, R.L., HOHENBOKEN, W.D. et al. Heterosis retention for live weight in advanced generations of a Hereford and Angus crossbreeding experiment. In: WORLD CONGRESS ON GENETICS APPLIED TO LIVESTOCK PRODUCTION, 3, 1986, Lincoln. Proceedings... Lincoln: University of Nebraska, 1986. v.11, p.301-307.

PEACOCK, F.M., KOGER, M., KIRK, W.G. et al. 1973. Comparative performances of various beef breeds and crosses in Florida. In: KOGER, M., CUNHA, T.J., WARNICK, A.C. (Eds.) Crossbreeding beef cattle - Series 2. Gainesville: University of Florida Press. p.43-48.

PEROTTO, D., CUBAS, A.C., ABRAHÃO, J.J.S. et al. Desempenho ponderal de animais Nelore e cruzas com Nelore. I. Período pré-desmama. In: REUNIÃO ANUAL DA SOCIEDADE BRASILEIRA DE ZOOTECNIA, 33, 1996, Fortaleza. Anais... Fortaleza: SBZ, 1996. p.124-126.

PEROTTO, D., JOSÉ, W.P.K., ABRAHÃO, J.J.dos S. Idade ao primeiro parto e intervalo entre partos de fêmeas bovinas Nelore e de mestiças Guzerá x Nelore, Red Angus x Nelore e Marchigiana x Nelore. In: REUNIÃO ANUAL DA SOCIEDADE BRASILEIRA DE ZOOTECNIA, 31, 1994, Maringá. Anais... Maringá: SBZ, 1994. p.176.

PEROTTO, D., ABRAHÃO, J.J. dos S, MOLETTA, J.L. et al. Crossbreeding systems for beef production in the NorthWest region of Paraná-Brazil. In: WORLD CONGRESS ON GENETICS APPLIED TO LIVESTOCK PRODUCTION, 6, 1998, Armidale. Proceedings... Armidale: University of New England, 1998a. 23:251-254.

PEROTTO, D., CUBAS, A.C., MOLETTA, J.L. et al. 1998b. Pesos ao nascimento e à desmama e ganho de peso do nascimento à desmama em bovinos das raças Charolesa e
Caracu e em mestiços gerados pelo cruzamento alternado Charolês x Caracu. R. Bras. Zootec., 27(4):730-737.

RAZOOK, A.G., LEME, P.R., PACKER, I.U. et al. Evaluation of Nelore, Canchim, Santa Gertrudis, Holstein, Brown Swiss and Caracu as sire breeds in matings with Nelore cows. Effects on progeny growth, carcass traits and crossbred productivity. In: WORLD CONGRESS ON GENETICS APPLIED TO LIVESTOCK PRODUCTION, 3, 1986, Lincoln. Proceedings... Lincoln: University of Nebraska, 1986. v.11, p.348-351.

ROBISON, O.W., McDANIEL, B.T., RINCON, E.J. 1981. Estimation of direct and maternal additive and heterotic effects from crossbreeding experiments in animals. J. Anim. Sci., 52(1):44-50.

SAS INSTITUTE INC. 1985. SAS User's guide:statistics. 5. ed. Cary, NC: SAS Inst. Inc. 956p.

SILVA, M.A., PEREIRA, F.A. 1986. Crescimento e desempenho reprodutivo de animais zebus e mestiços chianina-zebu. R. Soc. Bras. Zootec., 15(2):116-123.

SUNDSTROM, B., BARLOW, R., ARTHUR, P.F. Application of crossbreeding to beef production: opportunities, obstacles and challenges. In: WORLD CONGRESS ON GENETICS APPLIED TO LIVESTOCK PRODUCTION, 5, 1994, Guelph. Proceedings... Guelph: University of Guelph, 1994. 17:280-287.

TURNER, J.W. 1973. Comparison of straightbreds, single crosses, backcrosses and three-breed crosses of european and Brahman cattle. In: KOGER, M., CUNHA, T.J., WARNICK, A.C. (Eds.) Crossbreeding BeefCattle-Series 2. Gainesville: University of Florida Press. p.31-37.
Recebido em: 18/02/97 Aceito em: 26/11/98 